Article

\title{
Integrating Planned Behavior and Stage-of-Change into a Cycling Campaign
}

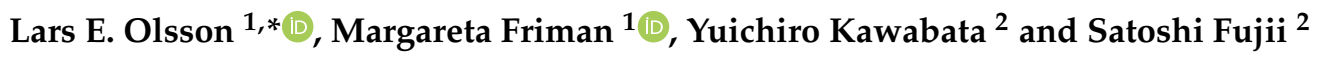 \\ 1 Service Research Center, Department of Social and Psychological Studies, Karlstad University, \\ SE-65188 Karlstad, Sweden; margareta.friman@kau.se \\ 2 Department of Urban Management, Kyoto University, Katsura, Nishikyo-ku, Kyoto 615-8540, Japan; \\ kawabata.yuichiro.8x@kyoto-u.ac.jp (Y.K.); fujii@trans.kuciv.kyoto-u.ac.jp (S.F.) \\ * Correspondence: lars.e.olsson@kau.se
}

Citation: Olsson, L.E.; Friman, M.; Kawabata, Y.; Fujii, S. Integrating Planned Behavior and Stage-ofChange into a Cycling Campaign Sustainability 2021, 13, 10116. https:// doi.org/10.3390/su131810116

Academic Editor: Gabriella Mazzulla

Received: 12 August 2021

Accepted: 6 September 2021

Published: 9 September 2021

Publisher's Note: MDPI stays neutral with regard to jurisdictional claims in published maps and institutional affiliations.

Copyright: (c) 2021 by the authors. Licensee MDPI, Basel, Switzerland. This article is an open access article distributed under the terms and conditions of the Creative Commons Attribution (CC BY) license (https:// creativecommons.org/licenses/by/ $4.0 /)$.

\begin{abstract}
A cycling campaign was assessed that used three different nudging conditions to progress people's stage of motivation to make travel behavioral changes. The results of three waves of survey data showed that this cycling campaign generally strengthened their stage of motivation to reduce car use and that this stage-change, in turn, reduced actual car use while increasing bike use. It was observed that an improvement of cognitive psychological mechanisms was positively related to people's motivation to change. Although the effect of the campaign was stronger just after it had ended (Wave 2), a reduction in car use, an increase in bike use, and an increase in the stage of motivation were still found three months after the campaign had ended. This is important as it shows that effects favoring sustainable travel last beyond the timeframe of the intervention. We conclude that travel interventions should aim to integrate processes that emphasize cognitive psychological mechanisms and people's motivation to change as these drive a sustainable behavioral change.
\end{abstract}

Keywords: bike campaign; nudging; motivation; TPB; travel behavior change; TTM; sustainable mobility

\section{Introduction}

Global climate change is underway, and there is broad agreement in climate research that manmade emissions of greenhouse gases are causing these changes (e.g., [1]). Cities are facing the challenge of implementing emission reductions, something that includes, for example, reduced car traffic [2]. This study provides new knowledge of how to motivate people to cycle and how to draw their attention to the bike as a mode of transport.

In an analysis of cycling in Sweden, an increase in urban areas has been observed, as well as a decrease in rural areas. Swedes cycle on average 5.3 million kilometers per day, which is a decline of 16 percent since the mid-1990s [3]. In general, Swedes cycled $0.7 \mathrm{~km}$ per person per day in 2019, which can be compared with $1.8 \mathrm{~km}$ per person per day in 2012/13. The average number of bike trips per person per day during March-August 2020 was not significantly different from the corresponding period during 2019 [4]. Thus, the Swedish government's goal of doubling cycling by 2025 [5] seems difficult to achieve thus far.

However, measures have been taken in Sweden to increase cycling. These initiatives have also been observed in other parts of Europe, as well as in Asia, America, Australia, and Africa, which have implemented strategies and plans for cycling (i.e., Cycling Master Plans). The Pan-European Master Plan for Cycling (see https: / / thepep.unece.org, accessed on 9 September 2021) is aimed at increasing cycling in every country and doubling cycling across the pan-European region by 2030. These actions have been accompanied by innovations in the cycling sector, e.g., electrification, cargo bikes, cycle highways, and bike-sharing schemes. In addition, a number of interventions have been implemented to induce a behavioral change. A recent scoping review presented by Kelly et al. [6], which includes 
129 studies, shows a broad spectrum of interventions for promoting cycling (education, persuasion, incentivization, coercion, training, restrictions, environmental restructuring, modeling, and enablement). Kelly et al. [6] conclude that there is satisfactory evidence that large-scale environmental restructuring (e.g., the implementation of road cycle networks) is effective in promoting cycling at the population level. However, as yet, less is known about how to promote cycling at the individual level, which is important knowledge for organizations, associations, and professional bodies working with environmental and sustainability issues.

The findings from this study contribute to the existing literature in two ways: First, although previous studies have examined the effectiveness of cycling interventions, few have looked at the effectiveness at the individual level. This study provides insights into the potential of three different nudging messages or conditions in progressing people's stage of motivation to make travel behavioral changes. We use the term nudge in accordance with Thaler and Sunstein [7] who state that a nudge is any aspect of a choice that alters people's behavior in a predictable way without forbidding any options. Furthermore, to count as a mere nudge, an intervention must be easy and cheap to avoid and not mandatory. This study also demonstrates the explanatory value of psychological mechanisms in better understanding transitions in motivational stages. In the following sections, we present the theoretical basis, including the relevant concepts (Section 2) and study objectives (Section 3), the dataset and methods (Section 4), the findings (Section 5), a discussion of our key findings and policy implications (Section 6), and our concluding remarks (Section 7).

\section{Theoretical Basis}

\subsection{The Stages of Change}

The transtheoretical model [8] (TTM) explains how behavioral change is a gradual, continuous, and dynamic process involving progress through a series of stages. At the bottom stage, there is no motivation to change (precontemplation). At the next stage, thoughts of making a change have started (contemplation). At the third stage, there is enough motivation for people to prepare for change (preparation). At the fourth stage, people are actively involved in behavioral change (action) due to being highly motivated, and, at the final stage, they are motivated to maintain their change (maintenance). Bamberg $[9,10]$ proposed the Stage Model of Self-Regulated Behavioral Change (SSBC) as another stage-based idea regarding pro-environmental behavior, specifically applicable to travel behavior. In this model, four stages are suggested: predecisional, preactional, actional, and postactional, which resonate with the TTM but differ as regards which stage a specific feature should be located in. Building upon the TTM and the SSBC, Olsson, Huck, and Friman [11] proposed a six-stage model wherein the bottom stage (of the TTM/SBCC) is divided into two independent stages; i.e., the last (predecisional denial) stage relating to people who do not see any reason to change and the second-last (predecisional inhibition) stage relating to people who believe it would be good to change but feel it is impossible to do so. Although it should be acknowledged that there is an ongoing debate around labeling and the number of stages in stage models, it is important to emphasize that they all follow the same logic and stage structure, from a weaker to a stronger motivation to change. A few studies have been conducted with TTM and cycling in focus. As will be shown in this section, they do not always build on each other, with different aspects in focus; hence, a somewhat scattered picture is presented.

A number of studies have been conducted with the aim of examining barriers that prevent a transition from one stage to another and in order to evaluate the potential for change in certain segments or areas [12-16]. Shannon et al. [15] performed a study in a university setting whereby both students and university staff were asked to rate the importance of potential motivators (e.g., improved health, enjoyment, or financial savings) for increased cycling. The same study also examined the likelihood that transport-related interventions (e.g., free emergency rides home or shower/change room facilities) would encourage them to adopt or maintain their use of active modes. By analyzing motivators 
and interventions by stage of behavioral change, it was possible to identify differences between the stages. As an example, contemplators emphasized the greater importance of barriers, particularly travel time and distance, than those at the action/maintenance stage. This result has been confirmed by Gatersleben and Appleton [14], as well as Fu et al. [13], who similarly conducted studies among university staff and students. Another study conducted among university employees [16] additionally showed that pre-contemplators, as well as females and support staff at all stages, perceived barriers to cycling to be greater than maintainers did, as well as males and academic staff at all stages. Nkurunziza et al. [17] showed that commuters at the early stages of change (pre-contemplation, contemplation, and preparation) frequently perceive more barriers than people at the later stages of change (action and maintenance).

Other studies diagnosed stage of change based on self-reported travel behavior (e.g., [18]), as well as responses to the questions "Have you thought about cycling to campus?" and "How likely are you to bike to campus in the coming six months?". These questions formed an index of stage-change membership. Thigpen et al. [18] then used their index to estimate a series of Bayesian multilevel ordinal logistic regression models, which included different blocks of explanatory variables. The aim was to test a number of hypotheses involving personal characteristics, travel attributes, perceived barriers, and travel attitudes to stage-change membership. Thigpen et al. [18] found that increased distance from campus is negatively associated with higher motivational stages; thus, distance is a deterrent to regular cycling commutes. Furthermore, stage-change membership varied with attitude to cycling. This result was dependent, however, on how the attitude question was framed. The strongest association between stage-change membership and an expressed attitude was found in the attitude statement: "I like riding a bike". This means that the more people like cycling, the higher the probability that they are at the later motivational stages (action and maintenance). Additionally, positive responses to the attitude statement: "I try to limit my (car) driving" were found to be both weakly and positively associated with the later motivational stages. An additional study was performed [19] in three Canadian cities. A diagnosis of stage-change membership was based on two questions focusing on the intent to cycle: (1) bike frequency over the past 12 months and (2) whether or not a bike was normally used to get around. Thigpen et al. [19] combined the stage-change model with a spatial geographical analysis and were thus able to identify "hot" areas with higher potential for biking behavior. Thigpen et al. [19] argue that identifying hot areas is useful when prioritizing, planning, and deciding on bike infrastructure.

Unlike previous studies focusing on barriers or diagnosis, Ahmed et al. [20] evaluated an intervention over time by means of including pre- and post-measurements. A total of 52 residents participated, with 40 being subjected to an intervention and 12 forming a control group. All 52 participants received the same information about the negative environmental consequences of driving. Participants subjected to the intervention also received customized travel plans, including tailored feedback in terms of a quantitative measure of their $\mathrm{CO}_{2}$ emissions based on their current travel behavior. A stage diagnosis measure focusing on car use intention was applied including two statements: (1) feelings about current car use and (2) intentions to replace some or all car trips with environmentally friendly alternatives. Thanks to pre- and post-measures, Ahmed et al. [20] were able to report the number of participants transferring to the motivational stage due to the intervention. The findings showed that some of the participants had progressed to higher stages, with a few regressing to lower stages and some remaining at the same stage. The findings indicate that forward progressive movement through the motivational stages is not always the case. The study of Ahmed et al. makes a valuable contribution as it follows the transformation from one stage to another as a consequence of a specific intervention. However, this study does not include any psychological explanations as to why the individual had become either more or less motivated after being exposed to customized travel plans that included tailored feedback. 
In summary, the stage-based framework has been applied with the aim of diagnosing the degree of motivation as regards initiating, increasing, or maintaining a specific cycling behavior. Findings reported from a number of studies show that the degree of motivation is an important factor for transformation as the higher stages increase the probability of cycling. Even if a number of conditions are the same (e.g., distance, socio-demographic), a certain degree of motivation is needed to implement a change. From previous studies, it is also possible to conclude that different types of barriers hinder a transformation in motivation: we have learned that the importance of various barriers varies with the individual's degree of motivation. Despite this support for the model, almost all studies are conducted using a single measure of stage, and not as a pre-test/post-test design. There is still a need to observe actual transformations in order to fully understand the power of an intervention. Furthermore, relatively few studies in cycling research have investigated the psychological mechanisms of significance in underpinning movement between stages.

\subsection{Psychological Mechanisms and Stage Change}

It has been argued that the combination of continuous models and stage-change models, e.g., the Theory of Planned Behavior (TPB) and the Transtheoretical Model of change (TTM), can explain the process of behavior change [21,22]. According to the TPB [23], behavior is guided by beliefs about the likely consequences of a behavior (defined as a favorable or unfavorable attitude), by beliefs about the normative expectations of others (the support of important others as well as inner values and principles), and by beliefs about the presence of factors that may support or hinder the performance of a behavior (defined as perceived behavioral control). An individual's behavior is emphasized by his/her intention (or motivation) to engage in a specific behavior. The more favorable the attitude and subjective norm, and the greater the perceived level of behavioral control, the stronger intention to perform the behavior in question [24].

So far in bicycle research, few studies have merged TPB and TTM. Forward [25] examined the mean value differences between TPB constructs at different motivation stages. The findings showed differences, e.g., perceived behavioral control was rated low at the precontemplation stage but high at the contemplation stage. The relationship between the different constructs was mainly linear. Three of the constructs also showed a quadratic relationship; i.e., subjective norm, perceived behavioral control, and intention. The findings suggest that it is the combination of measures, rather than the separate constructs, that distinguishes the stages.

In addition to a stage diagnosis, Biehl et al. [21] also included strategies for change in order to better understand the adoption process. Out of the ten strategies identified in the TTM, three were chosen; i.e., self-reevaluation (behavior change as an important part of self-identity), self-liberation (commitment linked to personal and social norms), and environmental reevaluation (defined as spatial ability, a sense of community, and evaluation of the built environment). The findings showed that identity formation and moral norm integration are important strategies throughout the behavior change process. Biehl et al. [21] show the importance of both demographic-personal and perceptual-attitudinal variables in determining stage-of-change membership.

\section{Study Objectives}

As noted above, there is scant research on combined models of planned behavior and stage-based motivation in relation to cycling. The specific objectives of the present research are thus threefold: (1) examining progress in the stage of change as a result of different nudging conditions, (2) investigating the role of psychological mechanisms in progressing the stage of change, and (3) examining possible long-term effects in terms of both mode use (car use and cycling) and progressing the stage of change. 


\section{Materials and Methods \\ 4.1. Participants and Procedure}

Ten companies and institutions throughout the County of Värmland (Sweden) volunteered to participate in a springtime 30-day bike-to-work campaign in 2018, organized by a County Council project group responsible for "sustainable travel in a growing County". The companies and institutions included staff from the local hospitals, consultancy agencies (city planning, engineering, and innovation), municipality services, and departments within the county public transport provider. Employees were offered the opportunity to voluntarily take part in the campaign; no one was forced to join. The campaign was designed in such a way that the volunteers managing to bike to work on at least ten days during the month of May (late spring) were included in a lottery whose prizes included bike equipment and clothing, as well as the star prize of a new bike.

Three different recruitment nudging messages were randomly distributed between the workplaces (referred to as nudging conditions in the analyses). All of these included the same information on how to participate and that the possibility existed to take part in the lottery. One important element of the information varied between them: One nudge emphasized the financial incentive, "Take part to win a bike"; another emphasized moral norms, "Let's do this for the environment"; and yet another emphasized social norms, "It's fun, let's do this together". The nudges were displayed on the intranet of the company/institution and on pamphlets lying on tables in lunchrooms and on coffee tables for a period of two to three weeks prior to the first of May. Examples of three pamphlets can be seen in Figure 1. On each nudging message, a picture of an ordinary citizen was displayed with a speech bubble featuring a message. The message was real in the sense that the person in the picture had taken part in a similar campaign another year and had given that message as the reason why he/she had participated. Hence, if someone were to meet, by chance, the person in the picture in real life, that person would understand that the message was not fiction.

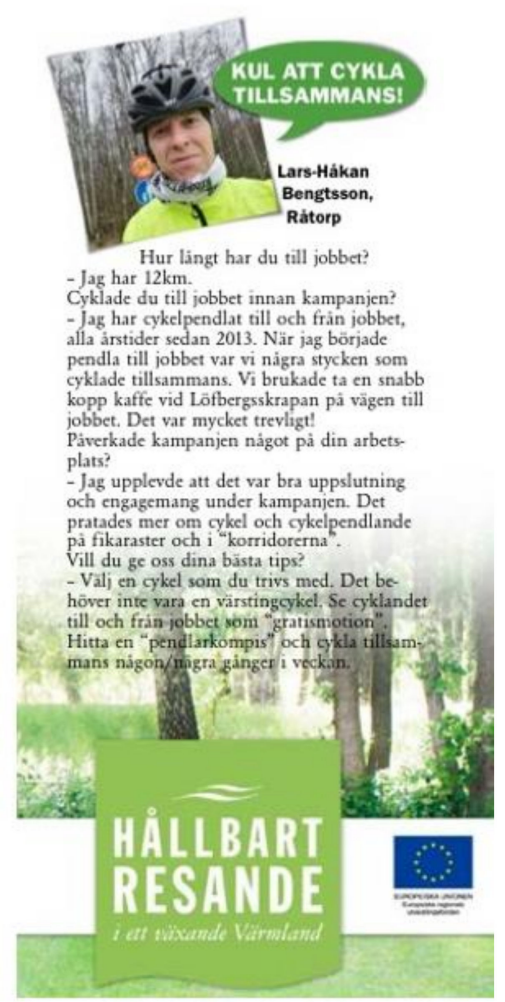

"It's fun to bike together" "I bike for the environment"

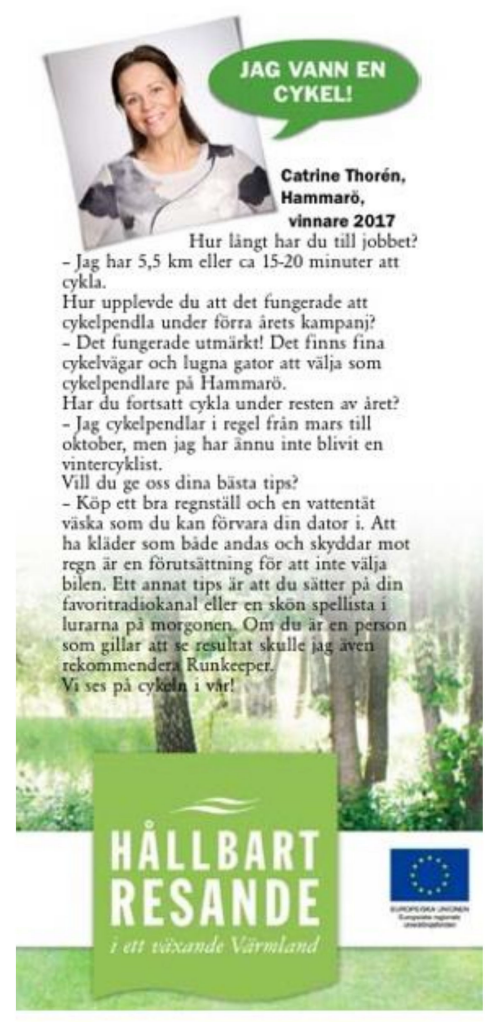

"I won a bike"

Figure 1. Examples of nudging messages on pamphlets. 
Those choosing to volunteer signed up by answering a short baseline survey that included sociodemographic information, current travel habits regarding work commutes, and a number of questions on psychological mechanisms related to travel (see the details under Section 4.2 Questionnaires). Two weeks after the campaign, a second wave of the survey was collected, which was then followed by a third wave of the survey three months after the second wave.

Three hundred and eighty volunteers took part in the campaign; 96 in the financial incentive nudge, 103 in the moral norms nudge, and 181 in the social norms nudge. During the second wave, drop-outs occurred, with 296 completing the survey, later falling to 172 during the third wave. The 172 who completed all three waves were included in the forthcoming analyses. In Table 1, age and gender are displayed across the three nudging conditions. As can be seen, the ages ranged from 23 to 66 years, with a mean of 45.3. About $78 \%$ were female, and the average distance to work was $8.02 \mathrm{~km}$.

Table 1. Distribution of age, gender, and distance to work across the nudging conditions.

\begin{tabular}{cccccccc}
\hline Nudge & n & & Age & & Women & \multicolumn{2}{c}{$\begin{array}{c}\text { Distance to Work } \\
\text { (in km) }\end{array}$} \\
\hline & & Mean & Min-Max & SD & \% & Mean & SD \\
\hline Financial & 44 & 47.32 & $23-64$ & 10.91 & 81.8 & 6.67 & 7.94 \\
incentive & 33 & 47.61 & $27-64$ & 10.76 & 81.8 & 5.04 & 10.76 \\
Moral norm & 95 & 43.59 & $23-66$ & 11.72 & 74.7 & 4.34 & 11.72 \\
Social norm & & & & &
\end{tabular}

\subsection{Questionnaires}

\subsubsection{Wave 1-Baseline Survey}

The baseline survey was conducted at the recruitment stage, just before the start of the bike-to-work campaign. This survey included questions in three different modules: (1) sociodemographic - containing questions on gender, year of birth, and type of workplace; (2) mode use-containing questions about current work commute habits during a normal week; and (3) psychological mechanisms related to mode use-containing questions relating to the stage of change, attitudes, personal and social norms, and perceived behavioral control.

\subsubsection{Wave 2-2 Weeks Post-Survey}

Wave 2 of the survey was conducted two weeks after the campaign. The questionnaire included four modules: (1) mode use-(i) current mode use during work commutes (replicating questions from Wave 1), (ii) on how many days they used their bikes during the campaign (0-30 days), and (iii) their distance in kilometers to their workplaces; (2) psychological mechanisms-replicating Wave 1, containing questions on the stage of change, attitudes, personal and social norms, and perceived behavioral control; (3) travel satisfaction during the bike campaign-containing questions on the cognitive and affective experiences of biking to work during the campaign; and (4) general remarks-relating to the campaign and answered using open-ended questions. In our forthcoming analyses, Modules 1 and 2 are included. Modules 3 and 4 are beyond the scope of the addressed research questions and will be analyzed and reported on elsewhere.

\subsubsection{Wave 3-3 Months Post-Survey}

Wave 3 was conducted three months after Wave 2 and included question in five modules: (1) mode use-replicating Wave 1 and Wave 2, (2) psychological mechanisms-replicating Wave 1 and Wave 2, (3) perceptions of barriers to bike use, (4) travel satisfaction during the bike campaign, and (5) motives for participating in the campaign. Our forthcoming analyses 
include Modules 1 and 2 as these specifically address the research questions. Modules 3, 4, and 5 will be analyzed and reported on elsewhere.

\subsection{Measures}

\subsubsection{Mode Use}

Questions were asked about self-reported mode use for commutes to work during a normal week at the time of the survey. The participants reported which mode they used each day of the week (Monday to Sunday), e.g., car, bike, walk, public transport, combined car and public transport, combined public transport and active modes (bike/walk), or any other modes or combinations of modes. A frequency index of 0-7 was computed for each of these categories $(0=$ no commute using the specific mode; $7=$ commuting to work on all days of the week using the specific mode). The same question format was used across all three waves. In the forthcoming analyses, car and bike use frequencies are targeted, in line with the purpose of the study.

\subsubsection{Stage of Change}

Building upon Olsson et al. [11] and Friman et al. [12], a measure of the stage-based motivation to change was used. This measure consists of one single question with six predefined statements, each corresponding to one of six specific stages of motivation. The same measure was used across the three waves. The question was phrased thus: "Which of the following statements best describes how you view your car journeys to and from work? Mark the statement that best fits your current situation", followed by the six statements: (1) (maintenance) As I don't travel by car, this question doesn't apply; (2) (postactional) I try to use other modes than car as much as possible, I'll maintain or reduce my already low car use in the coming months; (3) (actional) I most frequently use my car to go to work. My aim is to reduce my current car use. I know which journeys to replace and using which modes, but I haven't started to do so; (4) (preactional) I most frequently use my car to go to work. I'm thinking about reducing my car use but I'm unsure of how or when to do this; (5) (predecisional inhibition) I most frequently use my car to go to work. I'd like to reduce my car use but feel this is impossible; and (6) (predecisional denial) I most frequently use my car to go to work. I'm pleased with this and see no reason to reduce my car use.

\subsubsection{Psychological Measures}

Six well-established psychological measures were collected across the waves. As proposed by Ajzen [23] and further detailed in his conceptual and methodological considerations of the TPB [26], attitudes were measured using two items; i.e., one for instrumental attitudes and one for affective attitudes. Instrumental attitudes relate to the costs and benefits associated with the target behavior, whereas affective attitudes are emotional judgments related to the target behavior. In the case of instrumental attitude, we posed the question: "Choosing a different mode than car to get to work would work...", with the response being on a seven-point scale of $1=$ bad and $7=$ good, while in the case of affective attitude, we posed the question: "Choosing a different mode than car to get to work would feel ...", with the response being $1=$ bad and $7=\operatorname{good}[13]$.

A second mechanism from the theory of planned behavior is perceived behavioral control. This mechanism was measured using the statement: "For me, it would be easy to use another transport mode than car to get to work", with the answer being on a scale from 1 (do not agree at all) to 7 (fully agree) [12]. 
Norms were measured using three items, i.e., one for the moral norm and two for social norms. The moral norm was measured using the item: "Because of my personal values and principles, I feel a sense of obligation/guilt as regards not using the car to get to work". Social norms were divided into injunctive and descriptive, where the injunctive norm related to perceptions of how others (dis)approve and was measured by means of: "Most people that are important to me would support my choice to leave the car behind and use a different mode to get to work". The descriptive norm relates to perceptions of how other people behave in accordance with the desired norms and was measured by means of: "Most people that are important to me would leave the car behind and choose a different mode themselves". All three questions were answered on a scale ranging from 1 (do not agree at all) to 7 (fully agree) [13].

\section{Results}

\subsection{Mode Use}

Mode use (cycling versus car use) across the three nudging conditions and waves is summarized in Table 2. As can be seen, car use decreased independently of nudging condition between Waves 1 and 2 and then increased again between Waves 2 and 3. Cycling, on the other hand, increased between Waves 1 and 2 and then decreased between Waves 2 and 3. It should be noted that car use during Wave 3 was lower than the baseline (Wave 1), whereas cycling during Wave 3 was higher than the baseline (Wave 1).

Table 2. Means and standard deviations of car use and cycling across waves and nudging conditions.

\begin{tabular}{|c|c|c|c|c|c|c|}
\hline \multirow[t]{2}{*}{ Wave } & \multirow[t]{2}{*}{$\begin{array}{l}\text { Nudging } \\
\text { Condition }\end{array}$} & \multirow{2}{*}{$\begin{array}{c}\begin{array}{c}\text { Sample } \\
\text { Size }\end{array} \\
n\end{array}$} & \multicolumn{2}{|c|}{ Car Use } & \multicolumn{2}{|c|}{ Cycling } \\
\hline & & & $\mathbf{M}$ & Sd & $\mathbf{M}$ & Sd \\
\hline \multirow{4}{*}{1} & Financial & 44 & 0.31 & 0.39 & 0.54 & 0.43 \\
\hline & Social & 95 & 0.25 & 0.39 & 0.57 & 0.45 \\
\hline & Moral & 33 & 0.19 & 0.35 & 0.59 & 0.44 \\
\hline & Total & 172 & 0.26 & 0.38 & 0.57 & 0.44 \\
\hline \multirow{4}{*}{2} & Financial & 44 & 0.16 & 0.28 & 0.73 & 0.37 \\
\hline & Social & 95 & 0.11 & 0.25 & 0.72 & 0.39 \\
\hline & Moral & 33 & 0.04 & 0.13 & 0.82 & 0.34 \\
\hline & Total & 172 & 0.11 & 0.24 & 0.74 & 0.38 \\
\hline \multirow{4}{*}{3} & Financial & 44 & 0.18 & 0.29 & 0.65 & 0.40 \\
\hline & Social & 95 & 0.23 & 0.37 & 0.55 & 0.45 \\
\hline & Moral & 33 & 0.15 & 0.28 & 0.64 & 0.42 \\
\hline & Total & 172 & 0.20 & 0.34 & 0.59 & 0.43 \\
\hline
\end{tabular}

A 3 (nudging conditions) by 3 (waves) analysis of variance of car use and cycling, with repeated measurements of mode use, yielded significant main effects of waves, for car use, $F(2,168)=15.47, p<0.001$, and for cycling, $F(2,168)=22.13, p<0.001$. The main effect of nudging was not, however, significant, either for car use $(F(2,169)=1.12, p=0.32)$ or for cycling $(F(2,169)=0.45, p=0.60)$, while the same non-significant effects were observed during the interaction of nudging by wave (for car use $(F(4,338)=1.37, p=0.25$ ) and for cycling $(F(4,338)=1.12, p=0.35))$.

To further investigate differences in mode use between Waves 1 and 3, we conducted regression analyses with car use Wave 3 and cycling Wave 3 serving as dependent variables and nudging conditions, and car use Wave 1 and cycling Wave 1 serving as explanatory variables. Participating in the nudging conditions was operationalized as dummy variables, with financial incentives as the baseline. Separate models were estimated for car use and cycling. Table 3 gives the findings from the model for car use while Table 4 gives the findings from the model for cycling. A general observation here is that both car use and cycling during Wave 3 were marginally significantly larger in the nudging condition that focused on the social norm than in the nudging condition that focused on the financial 
incentives. This suggests that the decrease observed in car use between Waves 1 and 3, as well as the increase observed in cycling between Waves 1 and 3, was stronger in the financial incentive condition than in the social norm condition. The dummy for the moral norm condition was not significant in either model.

Table 3. Findings from regression analysis for car use $(n=171)$.

\begin{tabular}{ccccc}
\hline & Coefficient & $\begin{array}{c}\text { Standardized } \\
\text { Coefficient }\end{array}$ & $\mathbf{t}$ & $p$ \\
\hline Constant & 0.01 & - & 0.16 & 0.88 \\
Dummy for social norm condition & 0.09 & 0.13 & 1.80 & 0.07 \\
Dummy for moral norm condition & 0.03 & 0.04 & 0.52 & 0.60 \\
Car use Wave 1 & 0.55 & 0.63 & 10.55 & $<0.01$ \\
\hline \multicolumn{4}{c}{$\mathrm{R}^{2}=0.41$} \\
\hline
\end{tabular}

Table 4. Findings from regression analysis for cycling $(n=171)$.

\begin{tabular}{ccccc}
\hline & Coefficient & $\begin{array}{c}\text { Standardized } \\
\text { Coefficient }\end{array}$ & $\mathbf{t}$ & $p$ \\
\hline Constant & 0.34 & - & 5.48 & $<0.01$ \\
Dummy for social norm condition & -0.12 & -0.14 & -1.85 & 0.07 \\
Dummy for moral norm condition & -0.04 & -0.04 & -0.55 & 0.58 \\
Cycling Wave 1 & 0.58 & 0.59 & 9.62 & $<0.01$ \\
\hline & \multicolumn{5}{c}{$\mathrm{R}^{2}=0.36$} \\
\hline
\end{tabular}

Paired (Bonferroni corrected) $t$-test analyses at $p=0.05$ were performed between all pairs of waves; thus, the mean car use and mean cycling in Wave 1 were compared to the corresponding mean values in Waves 2 and 3. The mean in Wave 2 was also compared to the mean in Wave 3. The findings showed that all comparisons were statistically significant, except the mean cycling in Wave 1 compared to the mean cycling in Wave 3 . The mean car use in Wave 3 was marginally significantly smaller than the mean car use in Wave 1 . This implies that the nudging conditions do induce a statistically significant behavior change in the short run, but that the effect is slightly more uncertain in the long run. Although the increase in cycling did not statistically last beyond Wave 3, a marginally significant effect was detected for decreased car use, albeit diminishing over time.

Paired (Bonferroni corrected) $t$-test analyses at $p=0.05$ were also performed between all the mean pairs of nudging conditions. The findings similarly showed themselves to be statistically significant, although some more exceptions were observed. Neither car nor cycling achieved a statistically significant difference between Waves 1 and 3 in the social norm nudging condition or in the moral norm nudging condition. Additionally, in the financial nudging condition, the comparisons between Waves 2 and 3 for cycling and car use were not statistically significant. In the financial nudging condition, the difference in cycling between Waves 1 and 3 was not statistically significant either, but car use was statistically significant. These findings indicate that the observed behavior changes are not long lasting in the social and moral nudging conditions, but that they might last to a certain extent in the financial nudging condition.

\subsection{Stage of Change}

This study also included the theoretically based assumption that behavior change is induced by progress in the motivational stage of change. A cross-tabulation (Table 5) shows the number (frequency) of participants at each motivational stage (Stages 1 to 5) for Waves 1 and 3 (those in Stage 6 during Wave 1 were excluded as they did not see the point in taking part in the bike campaign and reducing their car use). As can be seen in the diagonal in Table 4, the majority did not change between Waves 1 and 3 . Among these, the greatest 
frequency can be found among the maintainers (Stage 1), i.e., those already reported as being fully motivated to not use their cars already during Wave 1 . For the remaining participants, $43.5 \%$ reported progress at the motivational stage, with $47.8 \%$ reporting no change and very small proportion (8.7\%) regressing in their stage of change toward less motivation. Interestingly, the greatest change (with over $70 \%$ making a stage progression) can be observed among the preactionals, i.e., those most frequently using their car to go to work, having started to think about reducing their car use but being unsure about how or when to do this. Among those in the postactional stage during Wave 1, who claim to try to use other modes than their cars as much as possible and who also state that they will maintain or reduce their already low car use in the coming months, $25 \%$ progressed to the maintenance stage, claiming that they no longer use their cars. It should be noted that a few at the maintenance, postactional, and actional stages regressed to the lower stages.

Table 5. Cross tabulation between stage membership of Waves 1 and 3 (at recruitment versus after the bike campaign).

\begin{tabular}{|c|c|c|c|c|c|c|c|}
\hline & & \multicolumn{5}{|c|}{ Stage during Wave 1} & \multirow[b]{2}{*}{ Total } \\
\hline & & Maintenance & Postactional & Actional & Preactional & $\begin{array}{l}\text { Predecisional } \\
\text { Inhibition }\end{array}$ & \\
\hline \multirow{8}{*}{$\begin{array}{c}\text { Stage during } \\
\text { Wave } 3\end{array}$} & maintenance & 72 & 12 & 0 & 1 & 0 & 85 \\
\hline & postactional & 9 & 31 & 1 & 20 & 1 & 62 \\
\hline & actional & 0 & 0 & 2 & 4 & 1 & 7 \\
\hline & preactional & 0 & 2 & 2 & 10 & 0 & 14 \\
\hline & $\begin{array}{l}\text { predecisional } \\
\text { inhibition }\end{array}$ & 0 & 3 & 0 & 0 & 1 & 4 \\
\hline & predecisional denial & 0 & 0 & 1 & 0 & 0 & 1 \\
\hline & Total & 81 & 48 & 6 & 35 & 3 & 173 \\
\hline & Progress rate & na. & $25.0 \%$ & $16.7 \%$ & $71.4 \%$ & $66.7 \%$ & \\
\hline
\end{tabular}

Note: Frequencies in the upper right corner marked in white represent those making progress in changing between Waves 1 and 3, hence, those increasing their stage of motivation. The diagonal field (light gray) represents those without a stage of change in either direction between Waves 1 and 3, while the field marked in dark gray represents those regressing to a lower degree of motivation.

Next, we look at the stage of change across the nudging conditions. The statistics for the stage of change across the nudging conditions and waves are summarized in Table 6. As can be seen, the means are low for most of the conditions, generally indicating relatively high stages of motivation. It can also be observed that those joining the campaign in response to the financial nudge averagely reported being in lower stages than those from the social and moral nudges.

Table 6. Means and standard deviations of stage across the nudging conditions and waves.

\begin{tabular}{ccccc}
\hline Wave & Nudging Condition & Sample Size & \multicolumn{2}{c}{ Stage of Change } \\
& & & M & Sd \\
\hline \multirow{3}{*}{1} & Financial & 44 & 2.16 & 1.29 \\
& Social & 95 & 1.99 & 1.21 \\
& Moral & 33 & 1.94 & 1.17 \\
& Total & 172 & 2.02 & 1.22 \\
\hline \multirow{2}{*}{2} & Financial & 44 & 1.70 & 0.88 \\
& Social & 95 & 1.67 & 0.90 \\
& Moral & 33 & 1.52 & 0.80 \\
& Total & 172 & 1.65 & 0.88 \\
\hline \multirow{2}{*}{3} & Financial & 44 & 1.73 & 0.92 \\
& Social & 95 & 1.91 & 1.20 \\
& Moral & 33 & 1.63 & 0.79 \\
& Total & 172 & 1.80 & 1.06 \\
\hline
\end{tabular}

Note: A lower number denotes a higher motivational stage of change. 
Since one aim of the present study was to investigate the potential long-term effects, a variable denoting progress in stage was calculated by subtracting the reported stage during Wave 1 from the reported stage during Wave 3. The progress in stage variable was added to a regression analysis. Car use during Wave 3 and cycling during Wave 3 served as dependent variables and nudging conditions (dummy coded), with progress in stage (between Waves 1-3), car use Wave 1, and cycling Wave 1 serving as explanatory variables. Participating in the nudging conditions was operationalized as dummy variables, with financial incentives as the baseline. Separate models were estimated for car use and cycling. Table 7 (car use) and Table 8 (cycling) show the findings. As can be seen, car use and cycling changed between Waves 1 and 3, and this change was significantly influenced by progress in the motivational stage $(p<0.01)$. The previously observed marginal significant effect for the moral nudging condition was no longer significant, neither for car use nor for cycling. This indicates that the marginal significant effect by the moral norm nudging condition is most likely mediated by progress in stage between Waves 1 and 3. As a consequence, we conducted an additional analysis of progress in stage with the aim of identifying the psychological factors of importance in the stage progress. These analyses are described in the next section.

Table 7. Findings from regression analysis of car use at Wave 3 accounting for stage progress $(n=171)$.

\begin{tabular}{|c|c|c|c|c|}
\hline & Coefficient & $\begin{array}{c}\text { Standardized } \\
\text { Coefficient }\end{array}$ & $\mathbf{t}$ & $p$ \\
\hline Constant & 0.02 & - & 0.52 & 0.61 \\
\hline Dummy for social norm condition & 0.05 & 0.07 & 1.14 & 0.26 \\
\hline Dummy for moral norm condition & 0.03 & 0.04 & 0.64 & 0.53 \\
\hline Progress in stage (Waves $1-3$ ) & -0.13 & -0.37 & -6.14 & $<0.01$ \\
\hline \multirow[t]{2}{*}{ Car use Wave 1} & 0.69 & 0.78 & 13.14 & $<0.01$ \\
\hline & & $\mathrm{R}^{2}=0.52$ & & \\
\hline
\end{tabular}

Table 8. Findings from regression analysis of cycling at Wave 3 accounting for stage progress $(n=171)$.

\begin{tabular}{ccccc}
\hline & Coefficient & $\begin{array}{c}\text { Standardized } \\
\text { Coefficient }\end{array}$ & $\mathbf{t}$ & $\boldsymbol{p}$ \\
\hline Constant & 0.23 & - & 3.77 & $<0.01$ \\
Dummy for social norm condition & -0.07 & -0.08 & -1.18 & 0.24 \\
Dummy for moral norm condition & -0.03 & 0.03 & -0.47 & 0.64 \\
Progress in stage (Waves 1-3) & 0.14 & 0.33 & 5.45 & $<0.01$ \\
Car use Wave 1 & 0.67 & 0.68 & 11.52 & $<0.01$ \\
\hline & \multicolumn{5}{c}{$\mathrm{R}^{2}=0.48$} \\
\hline
\end{tabular}

To further investigate progress in motivational stage between Waves 1 and 3, we conducted a regression analysis with stage at Wave 3 as the dependent variable, and with nudging conditions and stage at Wave 1 serving as explanatory variables. Participating in the nudging conditions was operationalized as dummy variables, with financial incentives as the baseline. Table 9 shows the findings. As can be seen, progress in stage at Wave 3 was marginally significantly larger in the social norm nudging condition than in the financial incentive nudging condition. This indicates that the financial incentive nudging condition had a marginally greater impact on the progress of stage of change than the social nudging condition. The dummy for the moral norm nudging condition was not significant. 
Table 9. Findings from regression analysis for progress in stage of change in wave $3(n=172)$.

\begin{tabular}{ccccc}
\hline & Coefficient & $\begin{array}{c}\text { Standardized } \\
\text { Coefficient }\end{array}$ & $\mathbf{t}$ & $p$ \\
\hline Constant & 0.53 & - & 3.24 & $<0.01$ \\
Dummy for social norm condition & 0.27 & 0.13 & 1.79 & 0.08 \\
Dummy for moral norm condition & -0.01 & 0.00 & -0.04 & 0.97 \\
Stage in Wave 1 & 0.56 & 0.64 & 10.88 & $<0.01$ \\
\hline & \multicolumn{3}{c}{$\mathrm{R}^{2}=0.42$} \\
\hline
\end{tabular}

To further test potential nuances in the stage progression between the waves for the three nudging conditions, a repeated measures analysis of variance was performed, which included all three waves. A three (nudging conditions) by three (waves) analysis of variance of progress in stage of change, with repeated measurements of stage, yielded significant main effects of the waves, $F(2,168)=14.35, p<0.001$. The interaction effect $(F(4$, $338)=1.15, p=0.33)$ and the main effect of the nudging condition $(F(2,169)=0.45, p=0.64)$ were not significant.

Paired $t$-test analyses at $p=0.05$ were performed between all pairs of waves, thus the stage in Wave 1 was compared to the stage in Waves 2 and 3, and the stage of Wave 2 was compared with Wave 3 . The findings showed statistically significant differences in all pairwise comparisons. This implies that the nudging conditions induce statistically significantly stage changes in both the short and long run, although the size of the change were slightly weaker in the long run.

Paired $t$-test analyses at $p=0.05$ were also performed between all pairs of nudging conditions. Similarly, the findings were statistically significant, except for the comparison between stages in Waves 1 and 3 in the social norm nudging condition, which was not significant. The results indicate that the progress in stage of change observed in the short run was not applicable over time to the social norm nudging condition. However, the progress in the stage of change continued over time in both the moral norm and financial incentive nudging conditions.

\subsection{The Role of Psychological Mechanisms in the Progress in Stage of Change}

The summary statistics (means and standard deviations) for self-rated attitudes (instrumental and affective), the norms (moral, social injunctive, and social descriptive), and the perceived behavioral control are shown for each respective wave and nudging condition in Table 10.

Table 10. Means and standard deviations for attitudes, norms, and perceived behavioral control.

\begin{tabular}{|c|c|c|c|c|c|c|c|c|c|c|c|c|c|c|}
\hline \multirow{3}{*}{ Wave } & \multirow{3}{*}{$\begin{array}{l}\text { Nudging } \\
\text { Condi- } \\
\text { tion }\end{array}$} & \multirow{3}{*}{$\begin{array}{l}\text { Sample } \\
\text { Size }\end{array}$} & \multicolumn{6}{|c|}{ Attitudes } & \multicolumn{4}{|c|}{ Norms } & \multirow{2}{*}{\multicolumn{2}{|c|}{$\begin{array}{c}\text { Perceived } \\
\text { Behavioral } \\
\text { Control }\end{array}$}} \\
\hline & & & \multicolumn{2}{|c|}{$\begin{array}{c}\text { Instrumental } \\
\text { Attitude }\end{array}$} & \multicolumn{2}{|c|}{$\begin{array}{l}\text { Affective } \\
\text { Attitude }\end{array}$} & \multicolumn{2}{|c|}{$\begin{array}{l}\text { Moral } \\
\text { Norm }\end{array}$} & \multicolumn{2}{|c|}{$\begin{array}{c}\text { Injunctive } \\
\text { Social Norm }\end{array}$} & \multicolumn{2}{|c|}{$\begin{array}{l}\text { Descriptive } \\
\text { Social Norm }\end{array}$} & & \\
\hline & & & $\mathrm{M}$ & $\mathrm{Sd}$ & $\mathrm{M}$ & $\mathrm{Sd}$ & M & $\mathrm{Sd}$ & $\mathrm{M}$ & $\mathrm{Sd}$ & M & $\mathrm{Sd}$ & M & Sd \\
\hline \multirow{4}{*}{1} & Financial & 44 & 6.16 & 1.46 & 6.61 & 0.99 & 4.77 & 2.10 & 5.80 & 1.80 & 4.48 & 1.86 & 5.70 & 1.62 \\
\hline & Social & 95 & 6.35 & 1.37 & 6.41 & 1.36 & 5.08 & 2.11 & 6.05 & 1.40 & 4.39 & 1.74 & 6.00 & 1.71 \\
\hline & Moral & 33 & 6.70 & 0.64 & 6.88 & 0.42 & 5.27 & 2.08 & 5.97 & 1.36 & 4.42 & 1.64 & 6.04 & 0.70 \\
\hline & Total & 172 & 6.37 & 1.29 & 6.55 & 1.16 & 5.04 & 2.10 & 5.97 & 1.50 & 4.42 & 1.74 & 6.05 & 1.57 \\
\hline \multirow{4}{*}{2} & Financial & 44 & 6.23 & 1.54 & 6.66 & 1.01 & 5.23 & 1.92 & 6.25 & 1.26 & 4.66 & 1.71 & 6.11 & 1.62 \\
\hline & Social & 95 & 6.36 & 1.42 & 6.54 & 1.20 & 5.27 & 1.95 & 6.07 & 1.39 & 4.72 & 1.60 & 6.05 & 1.65 \\
\hline & Moral & 33 & 6.82 & 0.53 & 6.91 & 0.38 & 5.67 & 1.87 & 6.33 & 0.92 & 4.76 & 1.62 & 6.21 & 1.47 \\
\hline & Total & 172 & 6.41 & 1.34 & 6.64 & 1.05 & 5.34 & 1.92 & 6.17 & 1.28 & 4.71 & 1.63 & 6.10 & 1.60 \\
\hline \multirow{4}{*}{3} & Financial & 44 & 6.05 & 1.61 & 6.41 & 1.56 & 4.66 & 2.27 & 6.20 & 1.44 & 4.43 & 1.95 & 5.64 & 2.01 \\
\hline & Social & 95 & 6.09 & 1.61 & 6.44 & 1.25 & 4.73 & 2.30 & 6.20 & 1.37 & 4.26 & 1.89 & 5.76 & 1.91 \\
\hline & Moral & 33 & 6.30 & 1.59 & 6.79 & 0.65 & 5.03 & 2.19 & 5.82 & 1.67 & 4.55 & 1.92 & 6.15 & 1.62 \\
\hline & Total & 172 & 6.12 & 1.60 & 6.50 & 1.25 & 4.77 & 2.26 & 6.13 & 1.45 & 4.36 & 1.90 & 5.80 & 1.88 \\
\hline
\end{tabular}


A three (nudging conditions) by three (waves) analysis of variance of the six psychological variables, with repeated measurements of the psychological variables, yielded significant main effects by wave for the instrumental attitude $(F(2,168)=3.23, p=0.04)$, moral norm $(F(2,168)=8.40, p<0.001)$, injunctive social norm $(F(2,168)=3.76, p=0.025)$, and descriptive social norm $(F(2,168)=3.67, p=0.028)$. These psychological variables changed in a positive direction between Waves 1 and 2, but decreased between Waves 2 and 3. A marginal significant interaction effect between the waves and nudging conditions was only found in the injunctive social norm $(F(4,338)=2.12, p=0.076)$.

To understand the role of psychological factors in the progress in stage of change, we conducted a regression analysis, with progress in stage of change at Wave 3 as the dependent variable and nudging conditions and with changes in psychological variables serving as explanatory variables. Changes in the included psychological variables (instrumental attitude, affective attitude, perceived behavioral control, injunctive social norm, and descriptive social norm) between Waves 1 and 3 were calculated by subtracting mean Wave 1 from mean Wave 3 in the case of each variable. Six new variables denoting change were thus created and included as explorative variables in the regression analysis. Table 11 presents the findings. As can be seen, the social norm nudging condition is still marginally significant. We also found that the change in perceived behavioral control had a significantly negative effect, and that instrumental attitude had a marginally significant negative effect. These findings indicate that positive changes in the perceived behavioral control and the instrumental attitudes toward cycling increase the intention to reduce current car use.

Table 11. Findings from regression analysis for progress in stage of change in Wave 3 accounting for changes in psychological variables between Waves 1 and $3(n=172)$.

\begin{tabular}{|c|c|c|c|c|}
\hline & Coefficient & $\begin{array}{c}\text { Standardized } \\
\text { Coefficient }\end{array}$ & $\mathbf{t}$ & $p$ \\
\hline Constant & 0.62 & - & 3.79 & $<0.01$ \\
\hline Dummy for social norm condition & 0.25 & 0.12 & 1.70 & 0.09 \\
\hline Dummy for moral norm condition & -0.06 & -0.02 & -0.34 & 0.73 \\
\hline Stage in Wave 1 & 0.51 & 0.58 & 9.67 & $<0.01$ \\
\hline Change in instrumental attitude & -0.09 & -0.13 & -1.83 & 0.07 \\
\hline Change in affective attitude & 0.00 & -0.01 & -0.07 & 0.94 \\
\hline Change in moral norm & 0.05 & 0.10 & 1.57 & 0.12 \\
\hline Change in perceived behavioral control & -0.09 & -0.14 & -2.14 & 0.03 \\
\hline Change in injunctive social norm & 0.03 & 0.04 & 0.57 & 0.57 \\
\hline Change in descriptive social norm & 0.02 & 0.03 & 0.46 & 0.65 \\
\hline
\end{tabular}

\section{Discussion}

A question posed in the present study was whether or not bike campaigns can change mode use and/or the degree of motivation to change. We combined models of planned behavior and stage-based motivation in relation to cycling, and we also examined progress in stage of change as a result of different nudging conditions. We also investigated the role of psychological mechanisms in progressing the stage of change, and we examined the possible long-term effects, both in terms of mode use (car use and cycling) and progress in the stage of motivation to change. In short, we found that the bike campaign generally strengthened the stage of motivation to reduce car use, and that this stage-change, in turn, reduced actual car use and increased bike use. Although the effect of the campaign was stronger just after it had ended (Wave 2), a reduction in car use and an increase in bike use was still to be found three months after the campaign had ended. This is important as it shows that effects favoring sustainable travel last beyond the timeframe of the intervention. 
While effects were still being observed three months after the campaign had ended, these effects were even stronger directly after the intervention. This decline gives rise to the question: How long will the stage and behavioral changes induced by the intervention last? Will behavior and the motivation to change stay at pre-campaign levels, or will they gradually revert? As we do not have any more data from the campaign with which to test this question, we can only make informed guesses. We would argue, however, in line with other stage-based models of motivation to change behavior, that motivation to change is not static and should be viewed as a volatile process. Hence, motivation and behavior may change in response to both external factors (e.g., interventions and campaigns) and internal ones (psychological mechanisms). A single intervention may be effective within a short timeframe but less so over time if not given additional attention and support. Even though the effects observed during the present study generally tended to strengthen motivation (stage progress), earlier research has shown that regressions to lower stages (less motivation to change) do occur (this being shown in Ahmed et al. [20] and in Friman et al. [12], in addition to being observed among some participants in this study, and even among those initially at the maintenance stage). We conclude that additional measures and interventions may be needed in practice either to sustain the new behavior or to increase the motivation to change again. It is important, however, to highlight the fact that significant progress in motivation was generally observed, and especially so among those at the preactional stage; in fact, over $70 \%$ of those at the preactional stage before the campaign had progressed to the higher motivational stages three months after the campaign had ended, while nobody at that stage regressed to the lower stages. People at this stage should be the prime target group for this type of campaign. Stage membership was defined using the statement: "I most frequently use my car to go to work. I'm thinking about reducing my car use, but I'm unsure of how or when to do this". Providing a "when and how" in the form of a cycle-to-work campaign opened up a possibility for them. The idea behind stagebased models of motivation to change is that each motivational stage is related, to varying degrees, to various processes aimed at triggering change $[27,28]$. For those at a preactional stage, the process of "trying a new behavior" is argued to be a relevant process, whereas other processes may be more relevant to other stages. From a managerial perspective, segmentation of groups of individuals based upon stage of motivation to change may be one way to identify to whom a specific campaign should be addressed. Such segmentation can thus be used for tailored information and actions to move people up the motivational ladder. This suggestion is in line with health-related stage-based guidelines; however, studies of processes related to specific motivational stages are still a weak spot in research on travel behavior and thus in great need of further research.

A novelty of this research is its focus on psychological mechanisms and their role in mode use and motivation to change. In line with earlier research (e.g., $[13,26])$, we observed that an improvement to and a strengthening of perceived behavioral control and instrumental attitude are positively related to motivation to change. Since both perceived behavioral control and instrumental attitude can be viewed as cognitive in nature, in contrast to norms and affective motives, our findings imply that cognitive mechanisms are of greater importance to the motivation to change mode use. Changes in norms did not have an effect on stage changes, contradicting Biehl et al. [21], who looked at strategies for stage change and found that self-liberation (commitment linked to norms) was of importance. Since we have no explanation for these contradictory findings, we highlight the need for further research. We did, however, observe that all the psychological variables measured, including norms, attitudes, and perceived behavioral control, showed a tendency toward supporting stage change for bike use in the short run, i.e., in Wave 2. This finding supports the ideas in the Theory of Planned Behavior, and in other theories of moral norms, such that these psychological variables induce behavioral change. In Wave 3 , the positive changes disappeared, however, for some variables, to even lower levels than initially. We can only speculate as to why this occurred. One possibility is that while the campaign strengthened the psychological variables and induced stage changes, there may also be other factors of 
greater importance once a new motivational stage has been reached, factors and processes that may vary between the predecisional and maintenance stages [28]. As also noted above, a more detailed account of the processes and psychological mechanisms at the different motivational stages is warranted and should be emphasized in future intervention studies.

No significant main effect was observed for the three nudging pamphlets and flyers used during the recruitment process. In the regression analysis of Wave 3 , the nudging social norms were, however, observed as being slightly less favorable with respect to car and bike use in the long run. If we were to make any policy recommendations based upon this, we would argue in favor of putting a greater emphasis on the moral and financial nudges. As the effects were rather weak, we will not, however, be making any claims as regards the potential of using nudging as a recruitment strategy in bike campaigns. More studies are needed to disentangle the potential of nudging in mode use interventions. During these kinds of efforts, nudges aimed at choices made during recruitment (before the start of the bike-to-work campaign) could be separated from, and tested against, nudges applied during the actual campaigns or interventions themselves. It would be of great interest to see if this kind of nudging would have an effect not only on behavior but also on the stage of motivation to change behavior in travel contexts.

\section{Conclusions}

The aim of this study was partly to investigate the effects of a cycle-to-work campaign using nudging for recruitment and partly to demonstrate the explanatory value of psychological mechanisms in order to better understand transitions in motivation to change. Although no specific nudging condition during recruitment outperformed the other, the campaign was effective overall as car use decreased, cycle use increased, and motivation to change mode use generally increased, even three months after the campaign had ended. For some people at lower motivational stages, the change was stronger. We thus conclude that cycle campaigns can have positive effects on both behavior and motivation to change and should be seen as a relevant complement to other programs and campaigns for sustainable travel.

Although we observed important and significant effects of the campaign, it is still important to acknowledge that it was conducted before the pandemic hit the earth. A similar campaign conducted during a crisis, such as a pandemic, may have resulted in other outcomes, perhaps causing even stronger effects as people want and need to travel with transport modes without crowding. Pandemics, natural disasters, and extreme weather are projected to increase in the future, circumstances that we need to adapt to and that will have an impact upon the effects of different campaigns. Pandemics may boost active travel, while weather and natural disasters may hamper the use of such modes. Hence, context needs to be considered when designing future interventions.

While taking context into account, we conclude that travel interventions should aim to integrate processes emphasizing psychological mechanisms and motivation to change since these are drivers of sustainable behavioral change.

Author Contributions: Idea, conceptualization and methodology, L.E.O., M.F.; formal analysis and interpretation, S.F., Y.K., L.E.O., M.F.; writing-original draft preparation, M.F., L.E.O., Y.K., S.F.; writing-review and editing, M.F., L.E.O., S.F., Y.K.; funding acquisition, L.E.O., M.F. All authors have read and agreed to the published version of the manuscript. All authors contributed substantially.

Funding: This research was financed by the Anne-Marie and Gustaf Ander Foundation (visiting professor's grant to S. Fujii at Karlstad University) and by the Swedish Energy Agency (Grants Nos. 46918-1 and 50504-1).

Institutional Review Board Statement: The study was conducted according to the guidelines of the Declaration of Helsinki. Ethical review and approval were waived for this study, due to that data were collected in 2017 by the County of Värmland two years before legal requirements for formal review in Sweden. Although a formal review protocol was not applicable, the County of Värmland followed their strict guidelines of data collection procedures, informed consent, and data storage. 
Informed Consent Statement: Informed consent was obtained from all subjects involved in the study.

Data Availability Statement: Restrictions apply to the availability of these data. Data was obtained from the County of Värmland and are available from the authors with the permission of the County of Värmland.

Conflicts of Interest: The authors declare no conflict of interest. The funders had no role in the design of the study; in the collection, analyses, or interpretation of data; in the writing of the manuscript; or in the decision to publish the findings.

\section{References}

1. Cook, J.; Oreskes, N.; Doran, P.T.; Anderegg, W.R.; Verheggen, B.; Maibach, E.W.; Rice, K. Consensus on consensus: A synthesis of consensus estimates on human-caused global warming. Environ. Res. Lett. 2016, 11, 048002. [CrossRef]

2. Gärling, T.; Ettema, D.; Friman, M. (Eds.) Handbook of Sustainable Travel; Springer: New York, NY, USA, 2014.

3. Transport Analysis. The Development of Cycling in Sweden, 1995-2014; Summary Report: Stockholm, Sweden, 2015.

4. Transport Analysis. Changes in Travel Patterns in Summary Sweden during the First Six Months of the Corona Pandemic; Summary Report: Stockholm, Sweden, 2020.

5. Regeringen. Strategi för Levande städer-Politik för en hållbar stadsutveckling. Skr. 2017/18:230. Stockholm. 2018. Available online: https: / / www.regeringen.se/4971fa/ contentassets/b5640fd317d04929990610e1a20a5383/171823000webb.pdf (accessed on 3 August 2021). (In Swedish)

6. Kelly, P.; Williamson, C.; Baker, G.; Davis, A.; Broadfield, S.; Coles, A.; Gill, J.M. Beyond cycle lanes and large-scale infrastructure: A scoping review of initiatives that groups and organizations can implement to promote cycling for the Cycle Nation Project. Br. J. Sports Med. 2020, 54, 1405-1415. [CrossRef] [PubMed]

7. Thaler, R.H.; Sunstein, C.R. Nudge: Improving Decisions about Health, Wealth and Happiness; Yale University Press: New Haven, CT, USA, 2008.

8. Prochaska, J.O.; DiClemente, C.C.; Norcross, J.C. In search of how people change: Applications to addictive behaviors. Addict. Nurs. Netw. 1993, 5, 2-16. [CrossRef]

9. Bamberg, S. Applying the stage model of self-regulated behavioral change in a car use reduction intervention. J. Environ. Psychol. 2013, 33, 68-75. [CrossRef]

10. Bamberg, S. Changing environmentally harmful behaviors: A stage model of self-regulated behavioral change. J. Environ. Psychol. 2013, 34, 151-159. [CrossRef]

11. Olsson, L.E.; Huck, J.; Friman, M. Intention for car use reduction: Applying a stage-based model. Int. J. Environ. Res. Public Health 2018, 15, 216. [CrossRef] [PubMed]

12. Friman, M.; Maier, R.; Olsson, L.E. Applying a motivational stage-based approach in order to study a temporary free public transport intervention. Transp. Policy 2019, 81, 173-183. [CrossRef]

13. Fu, T.; Mundorf, N.; Paiva, A.; Prochaska, J. Promoting behavior change among campus commuters (No. 1431-2016-118776). In Proceedings of the 53rd Annual Transportation Research Forum, Tampa, FL, USA, 15-17 March 2012.

14. Gatersleben, B.; Appleton, K.M. Contemplating cycling to work: Attitudes and perceptions in different stages of change. Transp. Res. Part A Policy Pract. 2007, 41, 302-312. [CrossRef]

15. Shannon, T.; Giles-Corti, B.; Pikora, T.; Bulsara, M.; Shilton, T.; Bull, F. Active commuting in a university setting: Assessing commuting habits and potential for modal change. Transp. Policy 2006, 13, 240-253. [CrossRef]

16. Van Bekkum, J.E.; Williams, J.M.; Morris, P.G. Cycle commuting and perceptions of barriers: Stages of change, gender and occupation. Health Educ. 2011, 111, 476-497. [CrossRef]

17. Nkurunziza, A.; Zuidgeest, M.; Brussel, M.; Van Maarseveen, M. Examining the potential for modal change: Motivators and barriers for bicycle commuting in Dar-es-Salaam. Transp. Policy 2012, 24, 249-259. [CrossRef]

18. Thigpen, C.G.; Driller, B.K.; Handy, S.L. Using a stages of change approach to explore opportunities for increasing bicycle commuting. Transp. Res. Part D Transp. Environ. 2015, 39, 44-55. [CrossRef]

19. Thigpen, C.; Fischer, J.; Nelson, T.; Therrien, S.; Fuller, D.; Gauvin, L.; Winters, M. Who is ready to bicycle? Categorizing and mapping bicyclists with behavior change concepts. Transp. Policy 2019, 82, 11-17. [CrossRef]

20. Ahmed, S.; Adnan, M.; Janssens, D.; Wets, G. A personalized mobility based intervention to promote pro-environmental travel behavior. Sustain. Cities Soc. 2020, 62, 102397. [CrossRef]

21. Biehl, A.; Ermagun, A.; Stathopoulos, A. Modelling determinants of walking and cycling adoption: A stage-of-change perspective. Transp. Res. Part F Traffic Psychol. Behav. 2018, 58, 452-470. [CrossRef]

22. Courneya, K.S.; Plotnikoff, R.C.; Hotz, S.B.; Birkett, N.J. Predicting exercise stage transitions over two consecutive 6-month periods: A test of the theory of planned behaviour in a population-based sample. Br. J. Health Psychol. 2001, 6, 135-150. [CrossRef] [PubMed]

23. Ajzen, I. The theory of planned behavior. Organ. Behav. Hum. Decis. Process. 1991, 50, 179-211. [CrossRef]

24. Bamberg, S.; Ajzen, I.; Schmidt, P. Choice of travel mode in the theory of planned behavior: The roles of past behavior, habit, and reasoned action. Basic Appl. Soc. Psychol. 2003, 25, 175-187. [CrossRef] 
25. Forward, S.E. Exploring people's willingness to bike using a combination of the theory of planned behavioural and the transtheoretical model. Eur. Rev. Appl. Psychol. 2014, 64, 151-159. [CrossRef]

26. Ajzen, I. Constructing a TPB Questionnaire: Conceptual and Methodological Considerations. 2002. Available online: http: / / citeseerx.ist.psu.edu/viewdoc/download?doi=10.1.1.601.956\&rep=rep1\&type=pdf (accessed on 29 August 2021).

27. Bartholomew, L.K.K.; Parcel, G.S.S.; Kok, G.; Gottlieb, N.H.H. Planning Health Promotion Programs; Wiley: San Franscisco, CA, USA, 2010.

28. Friman, M.; Huck, J.; Olsson, L.E. Transtheoretical model of change during travel behavior interventions: An integrative review. Int. J. Environ. Res. Public Health 2017, 14, 581. [CrossRef] [PubMed] 